\title{
Pattern Recognition Receptors: From the Cell Surface to Intracellular Dynamics
}

\author{
Denise Altenbach and Silke Robatzek \\ Max-Planck-Institut für Züchtungsforschung, Carl-von-Linné-Weg 10, 50829 Köln, Germany
}

Submitted 17 January 2007. Accepted 25 April 2007.

\begin{abstract}
Detection of potentially infectious microorganisms is essential for plant immunity. Microbial communities growing on plant surfaces are constantly monitored according to their conserved microbe-associated molecular patterns (MAMPs). In recent years, several pattern-recognition receptors, including receptor-like kinases and receptor-like proteins, and their contribution to disease resistance have been described. MAMP signaling must be carefully controlled and seems to involve receptor endocytosis. As a further surveillance layer, plants are able to specifically recognize microbial effector molecules via nucleotide-binding site leucinerich repeat receptors (NB-LRR). A number of recent studies show that NB-LRR translocate to the nucleus in order to exert their activity. In this review, current knowledge regarding the recognition of MAMPs by surface receptors, receptor activation, signaling, and subcellular redistribution are discussed.
\end{abstract}

Additional keywords: elicitor, nonhost resistance, PAMP.

Plants and animals have evolved sensitive perception systems to recognize microbe-derived products, such as small molecules and proteins. Over the past two decades, our knowledge about which microbial products act as general elicitors or avirulence proteins has expanded enormously. Until recently, research on plant immunity was focused mainly on gene-for-gene resistance; however, resistance triggered by general elicitors has received more attention lately. General elicitors, or microbe-associated molecular patterns (MAMPs), are conserved structures typical of whole classes of microbes that are sensed by a broad spectrum of host species. The notion of MAMPs is relevant to both potentially pathogenic microbes (often referred to as pathogen-associated molecular patterns [PAMPs]) as well as beneficial symbiotic organisms (He et al. 2006; Mackey and McFall 2006). MAMPs are recognized by cognate patternrecognition receptors (PRR) that trigger immediate defense responses leading to basal or nonhost resistance, or MAMP- or PAMP-triggered immunity (Chisholm et al. 2006; Jones and Dangl 2006). To date, all known PRR in plants are plasma membrane-resident proteins, allowing the perception of MAMPs to occur at the cell surface.

Specialized pathogenic microbes are able to overcome host immunity by either circumventing the detection of MAMPs (camouflage) or interfering with MAMP- or PAMP-triggered immunity (e.g., delaying, suppressing, or reprogramming host

Corresponding author: S. Robatzek; Telephone: +49 2215062 302; Fax: +49 2215062 353; E-mail: robatzek@mpiz-koeln.mpg.de responses). The secretion of so-called effector molecules promotes pathogen virulence and leads to susceptibility and, ultimately, the expression of symptoms (Grant et al. 2006). Most effector molecules have been identified as products of an avirulence gene specific to a certain microbial strain that are recognized by a matching resistance $(R)$ gene product specific to a certain plant cultivar (Ellis et al. 2000; Grant et al. 2006; Keen 1990; Rivas and Thomas 2005). This gene-for-gene mediated resistance has been referred to as effector-triggered immunity, and typically is accompanied by a local host cell death, the hypersensitive response (HR) (Chisholm et al. 2006; Jones and Dangl 2006). In contrast to PRR, receptor proteins recognizing effectors are found predominantly in the cytoplasm, although a few are surface receptors. This review focuses on recent advances in understanding the molecular mechanism and subcellular localization of receptors by which MAMPs are detected and immune responses are initiated.

\section{Microbial patterns.}

Typically, MAMPs represent structures that are essential for microbial life. These include cell wall and membrane constituents such as chitin and ergosterol from fungi, and $\beta$-glucans from oomycetes (Baureithel et al. 1994; Granado et al. 1995; Klarzynski et al. 2000). In addition, fungal xylanase and oomycete transglutaminase, with its conserved elicitor-active epitope Pep-13, both are secreted proteins that are recognized as MAMPs in solanaceaeous plants (Brunner et al. 2002; Nurnberger et al. 2004). Similarly, bacterial surface constituents such as lipopolysaccharides (LPS), which are the principal component of the outer membrane of gram-negative bacteria, and flagellin, the main building block of the bacterial motility organ, act as MAMPs in plants (Felix et al. 1999; Melotto et al. 2006; Meyer et al. 2001; Zipfel et al. 2004). The elicitoractive epitope within flagellin flg22 was identified from the conserved N-terminus (Felix et al. 1999). Moreover, two proteins normally located in the bacterial cytoplasm, namely coldshock protein (CSP) and elongation factor Tu (EF-Tu), trigger immune responses in members of Solanaceae and Brassicaceae (Felix and Boller 2003; Zipfel et al. 2006).

In addition to MAMPs, microbes produce specific molecules to reprogram host responses. For example, rhizobial bacteria are recognized specifically according to the Nod factors (modified chitin oligomers) that they produce (Riely et al. 2004). Most virulent microorganisms secrete effector molecules that are important for their pathogenicity. The majority of described bacterial effectors appear to be delivered into plant cells via the type III secretion system (Chisholm et al. 2006; Grant et al. 2006). Interestingly, type III-secreted effector proteins also have been identified in some species of rhizobia. Possibly 
these effectors lead to the suppression of host defenses, which might be essential in the early stages of symbiotic interactions (Skorpil et al. 2005; Viprey et al. 1998). Whereas no MAMPs have been detected in plant viruses, several viral effectors have been identified, including Tobacco mosaic virus (TMV) p50 helicase and Potato virus X (PVX) coat protein (Soosaar et al. 2005).

Several MAMPs, such as glucans, chitin, LPS, and flagellin, act in both plants and animals, but the individual epitopes that are recognized differ (Nurnberger et al. 2004; Zipfel and Felix 2005). It appears that chitin, LPS, and flagellin are recognized by a large number of plant families, whereas others, such as Pep-13, xylanase, and CSP, act more specifically on plant species belonging to only one family, a good example being EF$\mathrm{Tu}$ in the family Brassicaceae. However, even for flagellin perception, there is some degree of specificity characteristic for a plant family or species (Chinchilla et al. 2006; Sun et al. 2006). Whereas both Arabidopsis and tomato have highly sensitive perception systems for flg22, a peptide comprising its 15 $\mathrm{N}$-terminal amino acids, flg 15 , is highly active only in tomato (Felix et al. 1999). Further analysis dissecting the peptide in two parts revealed that binding and response could be attributed to distinct $\mathrm{N}$ - and $\mathrm{C}$-terminal domains, respectively (Meindl et al. 2000). This led to the proposition of the addressmessage concept, a two-step mechanism in which one part of the molecule mediates binding and another part triggers the activation of responses (Meindl et al. 2000). The address-message concept also can be applied to other MAMPs, such as CSP and EF-Tu (Felix and Boller 2003; Kunze et al. 2004).

\section{Receptors of microbial patterns.}

Receptors detecting microbial patterns can be divided into surface and intracellular receptors. The latter are the nucleotide-binding site (NB) leucine-rich repeat (LRR) class of receptors, hereafter referred to as NB-LRR. These are closely related to animal NOD-like receptor or CATERPILLER proteins (Inohara and Nunez 2003; Martin et al. 2003). They can be subdivided into coiled-coil (CC)-type and Toll and IL-1 (TIR)-type NB-LRR and, in plants, they appear to function exclusively in effector recognition. Surface receptors are known to detect both MAMPs and effectors and include receptor-like kinases (RLK), receptor-like proteins (RLP), and extracellular binding proteins. RLK reside in plasma membranes and are composed of a putative extracellular ligand-binding domain, a single transmembrane domain, and an intracellular serine/ threonine kinase domain. Thus, RLK are proteins with a "receptor" and a "signaling" domain in one molecule, and appear to be structurally related to animal receptor-tyrosine kinases (RTKs) (Shiu and Bleecker 2003). Similarly, RLP consist of an extracellular domain and a membrane-spanning domain. However, they lack an intracellular activation domain and, consequently, require interaction with adaptor molecules for signal transduction. RLP are structurally reminiscent of the Toll-like receptors (TLR) that mediate PAMP recognition in animals (Kopp and Medzhitov 2003; Underhill 2003). In mammals, several proteins serving as adaptor molecules linking TLR to kinase signaling cascades have been characterized, of which MyD88 and TRIF seem to be important players (Takeda 2005; Takeda and Akira 2003).

In total, 10 TLR have been described in mammals. In contrast, sea urchin possess a remarkably large repertoire of RLK and RLP, together compromising 222 TLR (Rast et al. 2006). In Arabidopsis, 610 RLK and 56 RLP have been identified (Fritz-Laylin et al. 2005; Shiu and Bleecker 2003), but only a limited number have been functionally characterized and even fewer are reported to act as immune receptors. Many Arabidopsis genes encoding RLK and RLP were found to be induced upon flg22 or EF-Tu treatment, suggesting that they may function as immune receptors (Zipfel et al. 2004). Indeed, 27 out of a total 216 LRR-RLK in Arabidopsis were found to be transcriptionally induced upon treatment with flg22 or EF-Tu, of which at least one novel PRR, namely EFR, has been identified (Zipfel et al. 2006). Among the upregulated genes, there also were three encoding RLK containing lysine motifs (LysM) in their extracellular domains, which potentially could recognize carbohydrate microbial structures. It appears that MAMPs also trigger enhanced expression of their own cognate receptors, as reported for flg22, EF-Tu, and chitin (Kaku et al. 2006; Zipfel et al. 2004, 2006). As with cell surface receptors, sea urchins and plants contain many more NB-LRR proteins than mammals (e.g., 203 in sea urchin and 149 in Arabidopsis, compared with only 20 in humans) (Meyers et al. 2003; Rast et al. 2006).

\section{Recognition of MAMPs by RLK.}

To date, very few RLK recognizing MAMPs have been characterized in plants. FLS2 (for Flagellin Sensing 2) has been genetically identified and used to demonstrate the importance of MAMP perception in plant immunity (Zipfel et al. 2004). Mutant plants devoid of the FLS2 receptor exhibited increased susceptibility upon surface inoculation with virulent Pseudomonas syringae pv. tomato DC3000, indicating that the FLS2/flg22 pathway significantly contributes to disease resistance. FLS2 encodes a membrane-resident RLK with 28 LRR in its extracellular domain, which appears to be highly glycosylated (Gomez-Gomez and Boller 2000). FLS2 was demonstrated to physically interact with the flg22 epitope and to determine ligand specificity (Chinchilla et al. 2006). The latter could be shown by expression of FLS2 in tomato, which resulted in the reconstitution of specificities in the flagellin perception system characteristic for Arabidopsis. Similarly, perception of bacterial flagellin in mammals mediated by TLR5 involves direct interaction with flagellin; however, the epitope recognized differs from flg22 and is formed by conserved Nterminal and C-terminal parts of the peptide chain (Smith et al. 2003). EFR, which, like FLS2, belongs to the LRR-RLK subgroup XII, was shown to be required for perception of bacterial EF-Tu. The EFR extracellular domain consists of $21 \mathrm{LRR}$ and was proposed to physically interact with the first 18 amino acids of the N-terminus of EF-Tu, the elf18 peptide. Nicotiana benthamiana, which lacks a perception system for EF-Tu, was shown to gain responsiveness to elf18 upon heterologous expression of EFR (Zipfel et al. 2006). Interestingly, biochemical purification of the Pep-13 binding site in parsley has revealed a partial sequence for another LRR-RLK that appears to function as a MAMP receptor (T. Nurnberger, personal communication).

\section{Recognition of other microbial and endogenous patterns by RLK.}

Pattern-recognition of symbiotic bacteria was shown to be mediated by two RLK identified from Lotus japonicus, NFR1 and NFR5, that contain two and three LysM motifs, respectively (Madsen et al. 2003; Radutoiu et al. 2003). Because mutant $n f r l$ and $n f r 5$ plants are impaired in their response to rhizobia and Nod-factors, NFR1 and NFR5 are prime candidates for being true receptors that recognize Nod factors. A related LysM-RLK, namely NFP, is involved in Nod-factor perception in Medicago spp. (Arrighi et al. 2006). Direct recognition of Nod-factors by NFP has been proposed (Mulder et al. 2006), but their physical interaction remains to be established. Another RLK regulating symbiosis (SYMRK) was placed downstream of NFR1/NFR5 (Yoshida and Parniske 2005).

In rice, Xa21 confers resistance to AvrXa21, an effector-like molecule widely conserved in Xanthomonas oryzae pv. oryzae 
strains (Lee et al. 2006; Wang et al. 1996). It is a typical RLK composed of 23 LRR in the extracellular domain. Other examples of RLK recognizing pathogen effectors are provided by rice $\mathrm{Xa26}$, $\mathrm{Pi}$-d2, and barley RPG1 (Brueggeman et al. 2002; Chen et al. 2006; Sun et al. 2004). Additionally, RLK have been reported to perceive stress-induced host molecules. Tomato SR160 is involved in systemin signaling, and Arabidopsis PEPR1 mediates responses toward the small wound-released peptide Pep1 (Montoya et al. 2002; Yamaguchi et al. 2006).

\section{RLP and extracellular binding proteins.}

Recently, a high-affinity binding protein for fungal-derived chitin-fragments, CEBiP, has been isolated from rice (Kaku et al. 2006). It is predicted to have two LysM domains in its extracellular part and a single transmembrane domain. Furthermore, it appears to be highly glycosylated. CEBiP was shown to mediate binding to chitin octamers and to be responsible for chitin-triggered immune responses. Binding of chitin octamers also could be competed with heptamers of chitin, but not with heptamers of chitosan, the deacetylated form of chitin. Thus, CEBiP is a prime candidate for being a chitin receptor. However, whether there are CEBiP homologues present in other plant species that similarly recognize chitin fragments remains to be addressed. In Arabidopsis, one of the LysM-RLK that are trancriptionally induced by flg22 or elf18 might perform this function.
Another RLP was found to recognize fungal xylanase but triggered an HR, which is more typical of host responses to pathogen effectors. Genetic mapping in tomato identified LeEix 1 and LeEix2, which are highly similar to each other and have extracellular domains of 31 LRR (Ron and Avni 2004). Silencing and complementation experiments showed that LeEix 2 is required for xylanase perception. Furthermore, fluorescently labeled xylanase was found to localize to the plasma membrane. Thus, LeEix appears to be responsible for xylanase recognition and response in tomato.

Most RLP have been reported to mediate responses to pathogen effectors. For example, tomato $C f$ genes confer resistance to Cladosporium fulvum strains (Takken et al. 1999). They encode LRR-type RLP; however, a physical interaction with their cognate Avr proteins could not be demonstrated, leaving open possible roles for extracellular binding proteins (Rivas and Thomas 2005; Rooney et al. 2005). Nevertheless, it has been shown that the specificity of Avr recognition is determined by the LRR domain, which depends on glycosylation (van der Hoorn et al. 2005). Recently, Avr9-triggered Cf-9 was reported to interact with a potential adaptor protein, connecting it to downstream signaling components (Nekrasov et al. 2006). Other examples of RLP include tomato Ve1 and Ve2, mediating resistance towards the fungus Verticillium spp. (Kawchuk et al. 2001).

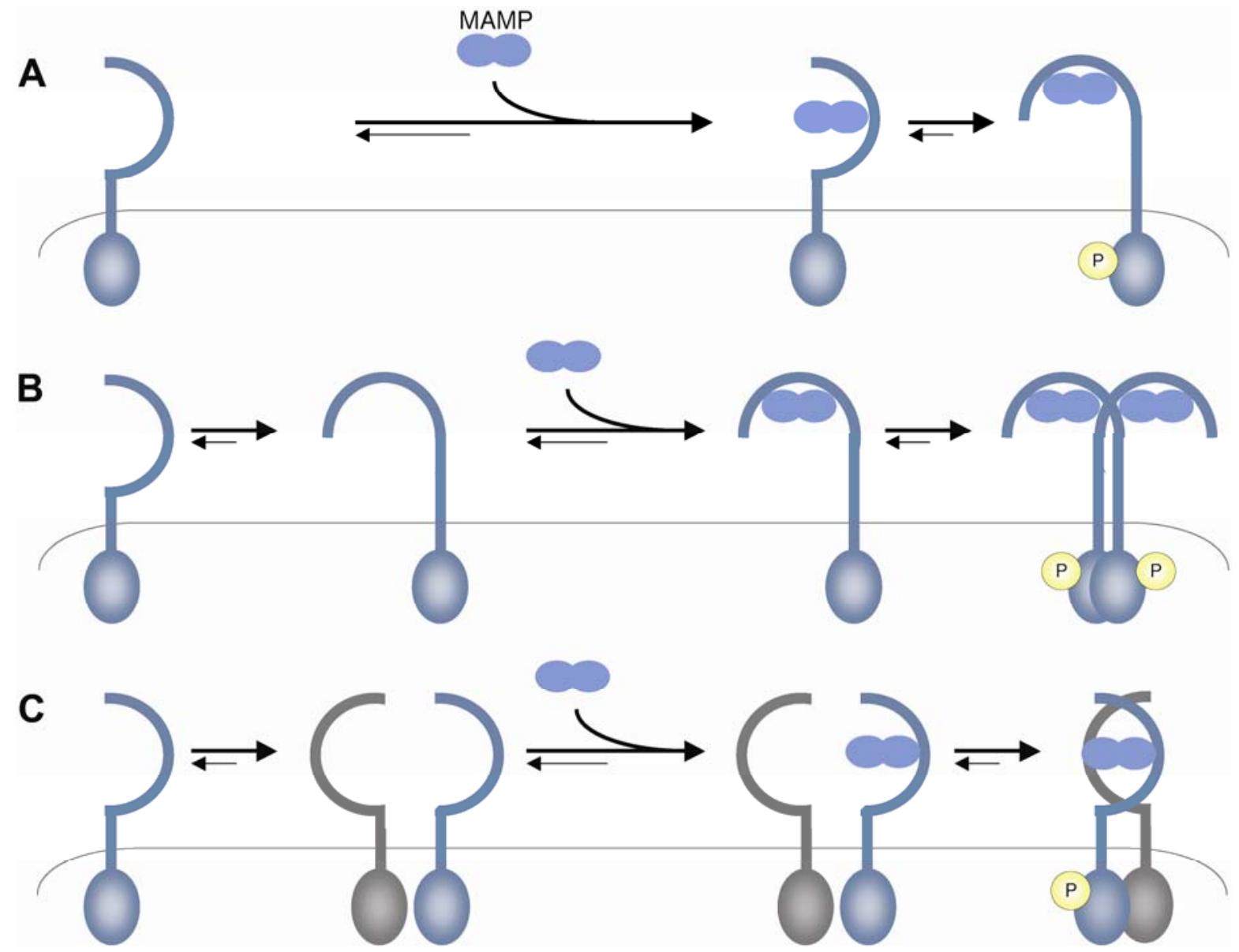

Fig. 1. Microbe-associated molecular pattern (MAMP)-induced structural changes leading to receptor dimerization and activation. We depict three possible steady-state equilibria between receptor monomers and homo- or heterodimers mediating physical interaction with a cognate MAMP. The membraneresident receptor either could contain a cytoplasmic signaling domain or function in association with a signaling component. A, A two-step activation mechanism is proposed according to the address-message concept. MAMP binding triggers an intrinsic conformational change resulting in receptor activation as indicated by phosphorylation. B, Homodimerization is proposed, based on TLR3-mediated ligand perception. A specific conformation enables MAMP association at one domain, which leads to formation of a stable active homodimer. C, In accordance with data from the BRI complex, heterodimerization into a stable complex occurs upon interaction with the cognate MAMP, which in turn drives activation of the receptor. Heterodimerization is proposed for the brassinosteroid, xylanase, and Nod-factor receptors, respectively. 
In soybean, a $\beta$-glucan-binding protein (GBP) was identified that lacks a transmembrane domain and predominantly localizes to the cytoplasmic face of the cell wall. Therefore, GBP represents a soluble extracellular binding protein which has been proposed to initially act on oomycete-derived heptaglucosides as a glucan hydrolase, releasing $\beta$-glucans that subsequently are perceived by a different domain of GBP (Fliegmann et al. 2004). The detection of GBP in vesicles at the plasma membrane and in the cytoplasm may indicate interaction with a transmembrane RLK or RLP. Similarly, in mammals, the extracellular binding protein CD14 was shown to bind LPS (Husebye et al. 2006). Through interaction with transmembrane TLR4, CD14 translocates to the cytoplasm and responses to LPS are induced. Whereas TLR4 functions as the cognate LPS receptor in mammals, to date no LPS-receptor has been identified in plants. However, there is indirect evidence for a membrane-localized LPS receptor. Fluorescently labeled LPS was found to bind to tobacco cells and became internalized into endocytic vesicles, consistent with a receptor-mediated process (Gross et al. 2005). The receptor may be among the LPS-induced genes encoding RLK (Sanabria and Dubery 2006).

\section{Activation of RLK and RLP.}

The address-message concept proposed for MAMPs might be reflected in a two-step receptor activation mechanism. This could involve either two different proteins or intrinsic modifications in a single protein (Fig. 1). FLS2 itself is sufficient to both mediate flg22 binding and determine specificity (Chinchilla et al. 2006), and there is no evidence for the involvement of additional proteins in flg22 binding. Thus, the two-step activation mechanism may involve conformational changes within FLS2. In turn, this could lead to homo- or heterodimerization with components of a signaling receptor complex. Assembly of such complexes has been described for animal RTKs and TLR (Schlessinger 2000; Shi and Massague 2003; Underhill 2003). Most TLR reside as monomers in the cell membrane, and form di- or oligomers upon ligand binding (Ozinsky et al. 2000). The crystal structure of the human TLR3-LRR domain revealed the presence of a highly glycosylated horseshoe-shaped structure (Choe et al. 2005). Ligand binding was demonstrated to occur at the glycosylation-free lateral face encompassing a domain at the C-terminus, which in turn promoted oligomerization of TLR3 (Bell et al. 2006). Recently, the ligand-binding domain of TLR5 was identified by exploring species-specific differences in flagellin recognition (Andersen-Nissen et al. 2007). The flagellin-TLR5 interaction interface appears within a conserved lateral path, which is located on the nonglycosylated face, as found with TLR3. In accordance with the TLR3 model, the identified conserved lateral path may be involved in TLR5 dimerization.

Plant RLK also are likely to undergo receptor oligomerization (Hubbard 1999). To date, the best characterized RLK is Brassinosteroid Insensitive 1 (BRI1), which recognizes brassinolides via physical interaction with the island region of its LRR domain (Kinoshita et al. 2005). BRI1 was found to homodimerize, and appears in a multimeric complex with two other RLK with much smaller LRR domains, namely BRI1associated kinase 1 (BAK1) and the somatic embryo receptor kinase 1 (SERK1) (Karlova et al. 2006; Russinova et al. 2004; Wang et al. 2005). The CLAVATA complex is formed by a heterodimeric interaction between an RLK and an RLP (Fiers et al. 2006). Many PRR, including FLS2, EFR, and Cf proteins, contain conserved cysteine residues flanking the LRR domain, which could form intermolecular disulfide bridges allowing stable homo- or heterodimerization or coupling to signaling molecules (Kolade et al. 2006; van der Hoorn et al. 2005).
However, the evidence for complex formation is limited. NFR1 and NFR5 have been proposed to function as a heterodimer, because NFR5 lacks the kinase activation loop and might operate as a co-receptor together with NFR1 (Riely et al. 2004). Similarly, LeEix 1 and LeEix 2 receptors may act cooperatively. Although both were found to mediate xylanase binding individually, only LeEix 2 was capable of eliciting an HR (Ron and Avni 2004).

In general, many receptor kinases phosphorylate residues on the receptor itself as well as components of the downstream signaling pathways (Hubbard and Till 2000; Schlessinger 2000). Phosphorylation has been demonstrated for several plant RLK. For example, brassinolide was found to induce BRI1 phosphorylation in vivo, which requires its juxtamembrane (JM) domain and is negatively regulated by its C-terminus (Wang et al. 2001; Wang et al. 2005). In addition, BRI1 exhibited transphosphorylation activity in vitro. In RTKs, transphosphorylation was shown to control ligand-induced dimerizations and, thus, could play a role in BRI1 complex formation (Warren and Landgraf 2006). SYMRK is regulated via its phosphorylation status and the crucial residues are conserved among many RLK (Yoshida and Parniske 2005). Autophosphorylation was shown for Xa21 on multiple serine/threonine residues in vitro, and this was proposed to prevent degradation of Xa21 (Xu et al. 2006). Mutation of the respective residue in the JM-domain led to compromised resistance toward normally virulent bacteria. The FLS2 kinase domain also was found to be capable of autophosphorylation in vitro (Gomez-Gomez et al. 2001). Interestingly, a kinase-inactive variant led to instability of the FLS2 protein (Robatztek et al. 2007). Furthermore, mutational analysis revealed three potentially phosphorylated residues that are important for FLS2 function (Robatzek et al. 2006). A survey of in vivo phosphorylation sites in the JM-domain of RLK revealed no apparent common motif, which suggests that each RLK may be regulated differentially (Nuhse et al. 2004).

\section{Signaling of RLK and RLP.}

Stimulation of membrane-resident immune receptors by their cognate ligands results in a chain of signal transduction events, including activation of a mitogen-activated protein kinase (MAPK) cascade, function of WRKY transcription factors, and changes in gene expression (Asai et al. 2002; Kunze et al. 2004; Ligterink et al. 1997; Romeis et al. 2000; Zipfel et al. 2004). Despite this, there remain many unanswered questions concerning how surface receptors are connected to signaling molecules and how signaling eventually is translated into changes in gene expression. Receptor-mediated signaling involving endocytic processes is a widespread phenomenon demonstrated in yeast, animals, and, lately, also in plants. For example, the mammalian epidermal growth factor receptor (EGFR) seems to trigger signaling pathways initiated at the plasma membrane and at endosomes (Citri and Yarden 2006). Signaling by the internalized receptors was shown by blocking endocytosis, which drastically reduced MAPK activation (Vieira et al. 1996). MAPK signaling depends on the endosomal adaptor protein $\mathrm{p} 14$, which is needed to recruit the MAPK scaffolding protein MP1 (Teis et al. 2002). Further investigations revealed that mammalian RTK receptors ultimately localize to the nucleus, which may be mediated by endocytosis (Lin et al. 2001; Lo et al. 2006). Thus, chemical inhibition of receptor internalization suppressed nuclear entry of EGFR (Lo et al. 2006). In addition, RTKs can be processed within their extracellular domains and, subsequently, their cytoplasmic domains can be proteolytically released and targeted to the nucleus (Ni et al. 2001). Thus, surface receptors potentially could interact with components of the transcription machinery without many signaling steps in between. Proteolytic cleavage has been re- 
ported for rice Xa21, probably occurring in the JM domain, and is thought to retain the extracellular and transmembrane portions in the membrane while releasing the cytoplasmic domain from the membrane (Xu et al. 2006). Recently, Xa21 was shown to interact with a ubiquitin E3 ligase, a substrate of Xa21 kinase, which may be responsible for Xa21 stability (Wang et al. 2006).

\section{Subcellular dynamics of RLK and RLP.}

Recently, MAMP-induced endocytosis was demonstrated for receptors of the innate immune system in both animals and plants. In animals, LPS was found to trigger endocytosis of its recognition complex, consisting of CD14, MD-2, and TLR4. The latter carries three copies of the tyrosine-based tetrapeptide motif $\mathrm{Yxx} \Phi$, a known endocytic-sorting signal (Husebye et al. 2006). In the absence of LPS, TLR4 and MD2 were found to undergo repeated recycling. Induced TLR4 endocytosis depends on clathrin and dynamin, a large GTPase, which interacts with phospholipids and associates with the cytoskeleton to mediate formation of clathrin-coated vesicles. Furthermore, TLR4 endocytosis involves ubiquitination and the ubiquitin-binding endosomal sorting protein Hrs, which interacts with the endosomeassociated complex (ESCRT-I, -II, and -III). LPS was found to co-internalize together with its receptor complex. Inhibition of TLR4 endocytosis resulted in an increased LPS response, which suggests that the TLR4 signal is transmitted from the cell membrane and that endocytosis of TLR4 plays a role in attenuating LPS signaling. Interestingly, signaling adaptor molecules such as TRAM could be detected at TLR4 endosomes, indicating that signaling may occur at this location also.

Whereas, in animals, endocytosis of surface receptors is well established (Warren and Landgraf 2006), receptor endocytosis in plants is a newly emerging field of research. In Arabidopsis, endocytosis has been observed for polar auxin transport mediated by PIN1, for the receptor complex BRI1 and BAK1 recognizing brassinosteroides, and, recently, for the immune receptor FLS2 (Geldner and Jurgens 2006). Flg22 was found to specifically trigger accumulation of the normally plasma membrane-resident FLS2 into intracellular vesicles (Robatzek et al. 2006). This appeared to be specific because inactive flg22 peptide variants and the unrelated MAMP EFTu did not stimulate FLS2 endocytosis. Interestingly, treatment with a strong antagonist seemingly increased the amount of membrane-resident FLS2, suggesting that recycling of the receptor may occur. Induced FLS2 endocytosis was dependent on cytoskeleton and proteasome function. FLS2 lacks a YxxФ motif, but contains a PEST-like motif, which is reported to mediate receptor endocytosis via mono-ubiquitination in yeast and mammals (Hammond et al. 2001). Single mutations either in the PEST-like motif or at a conserved, potentially phosphorylated, residue in the JM region impaired FLS2 endocytosis (Robatzek et al. 2006). FLS2-labeled vesicles could be observed only for a limited time, indicating that the internalized receptor is targeting for degradation. Nevertheless, accumulation of activated FLS2 into intracellular compartments might be required for some of the downstream signaling events. The FLS2 mutant variants described above were not only defective in endocytosis but also affected in flg22 responses. Moreover, Wortmannin, a chemical interfering with the formation of prevacuolar compartments, was found to block FLS2 endocytosis and also caused a significant reduction in flg22-triggered MAPK activation (Chinchilla et al. 2007). Taken together, these findings strongly support the notion that FLS2 endocytosis contributes to flg22 signaling.

Screening for chemicals interfering with flg22-triggered promoter activities led to the identification of Cantharidin and Triclosan as inhibitors of FLS2 endocytosis (Serrano et al.
2007). Cantharidin targets type $2 \mathrm{~A}$ protein phosphatases, and this suggests a role for phosphatases in receptor endocytosis. The kinase-associated protein phosphatase (KAPP) has been described to interact with FLS2 in vitro, and was found to accelerate accumulation of SERK1 in endosomes (GomezGomez et al. 2001; Shah et al. 2002). Triclosan likely affects a subunit of the fatty acid synthase type II complex, MOD1, in Arabidopsis, thereby potentially interfering with signaling lipids (Serrano et al. 2007). It is worth noting that, in mammals, phospholipase D was shown to influence receptor endocytosis via interaction with dynamin (Lee et al. 2006), and a tomato phospholipase D relocalized to vesicle-like structures upon xylanase treatment (Bargmann et al. 2006). In addition, dynamins were found to be phosphorylated in a flg22- and xylanasedependent manner (Benschop et al. 2007).

Receptor endocytosis may be a more general feature in plant immunity (Fig. 2). Thus, Arabidopsis EFR, tomato Ve, Cf proteins, and LeEix2 all carry the $\mathrm{Yxx} \Phi$ motif in their C-terminal parts (Fritz-Laylin et al. 2005; Kawchuk et al. 2001; Ron and Avni 2004; Zipfel et al. 2006). Mutation of this motif in LeEix 2 led to an impaired response, indicating that endocytosis might be involved in xylanase signaling. Furthermore, GBP was detected in cytoplasmic vesicles, again suggestive of an endocytic process (Fliegmann et al. 2004). Although the cognate receptor remains to be determined in plants, LPS also was found in endocytic vesicles (Gross et al. 2005). Surface receptors undergo a highly dynamic subcellular redistribution; thus, upon synthesis, they are secreted to the plasma membrane, where they then are subjected to repeated recycling and stimulus-dependent or -independent endocytosis, all of which has to be in balance with exocytic processes. Depletion of receptors from the cell surface via endocytosis might be a central switch in signaling during immune responses. In addition, it may provide a mechanism to prevent a continuous immune response by the clearance of MAMPs from the extracellular environment (McCoy et al. 2004).

\section{Conclusions and perspectives.}

The ability to monitor microbial growth at the cell surface is pivotal for plant fitness. Devoid of an antigen-presenting adaptive immune system, plants have evolved a large repertoire of potential immune receptors that recognize MAMPs or mediate effector perception. The few MAMP receptors identified in plants are all surface receptors that physically interact with their cognate ligands. However, the MAMP binding domains of plant PRR remain to be characterized. Moreover, the crystal structures of RLK and RLP are required for a detailed understanding of molecular changes during receptor activation. Indirect evidence points to a two-step mechanism of MAMP binding and receptor activation which involves intrinsic conformational changes, dimerization, or recruitment of a co-receptor. Oligomerization with a co-receptor might be required for stabilizing ligand binding or for signal transduction or signal amplification. MAMP perception triggers activation of an MAPK cascade and transcriptional changes, but how PRR are connected to components of cytoplasmic signaling cascades and nuclear activities remains to be determined. Recent studies on the subcellular redistribution of FLS2 point to a link between MAMP receptors and signaling components at endosomes. It seems that MAMP-induced endocytosis is a general process that could modulate the immune response (Fig. 2). Whether plant surface receptors also exhibit a nuclear localization, as in mammals, is unclear.

Activation of the intracellular NB-LRR receptors also seems to involve conformational changes and oligomerization triggered by ligand binding (Linhoff et al. 2001; Inohara and Nunez 2003; McHale et al. 2006). Recently, a picture has begun to 
emerge of how NB-LRR activation is transduced to activate transcriptional changes. A number of reports show that mammalian and plant NB-LRR exert their activities in the nucleus; for example, through association with DNA-binding proteins (Burch-Smith et al. 2007; Shen et al. 2007; Ting et al. 2006). Tobacco N, a TIR-NB-LRR, and barley MLA10 were found to be targeted to the nucleus and, in both cases, this was required for disease resistance. Furthermore, effector-triggered MLA10 associated with two WRKY transcription factors, which negatively regulated normally MAMP-responsive genes (Shen et al. 2007). These findings provide a mechanistic link between MAMP- and effector-triggered immunity, and suggest that NB-LRR signaling might not employ many components, but rather take place immediately in the nucleus (Fig. 2). It seems that nuclear translocation of intracellular immune receptors is a more general mechanism. Thus, Arabidopsis RRS1, a composite WRKY-TIR-NB-LRR, also was reported to localize to nuclei upon effector trigger (Deslandes et al. 2003). Moreover, proteins with a function in nuclear import were identified as suppressors of SNC1, a receptor of the TIR-NB-LRR-type (Palma et al. 2005; Zhang and Li 2005).

These recent advances highlight the importance of immune receptor redistribution in the perception of both MAMPs and effectors. Surface-resident receptors recognizing MAMPs or effectors became internalized into endocytic vesicles whereas intracellular NB-LRR travel to the nucleus. Thus, the dynamic subcellular redistribution of receptors is emerging as a key feature of MAMP signaling.

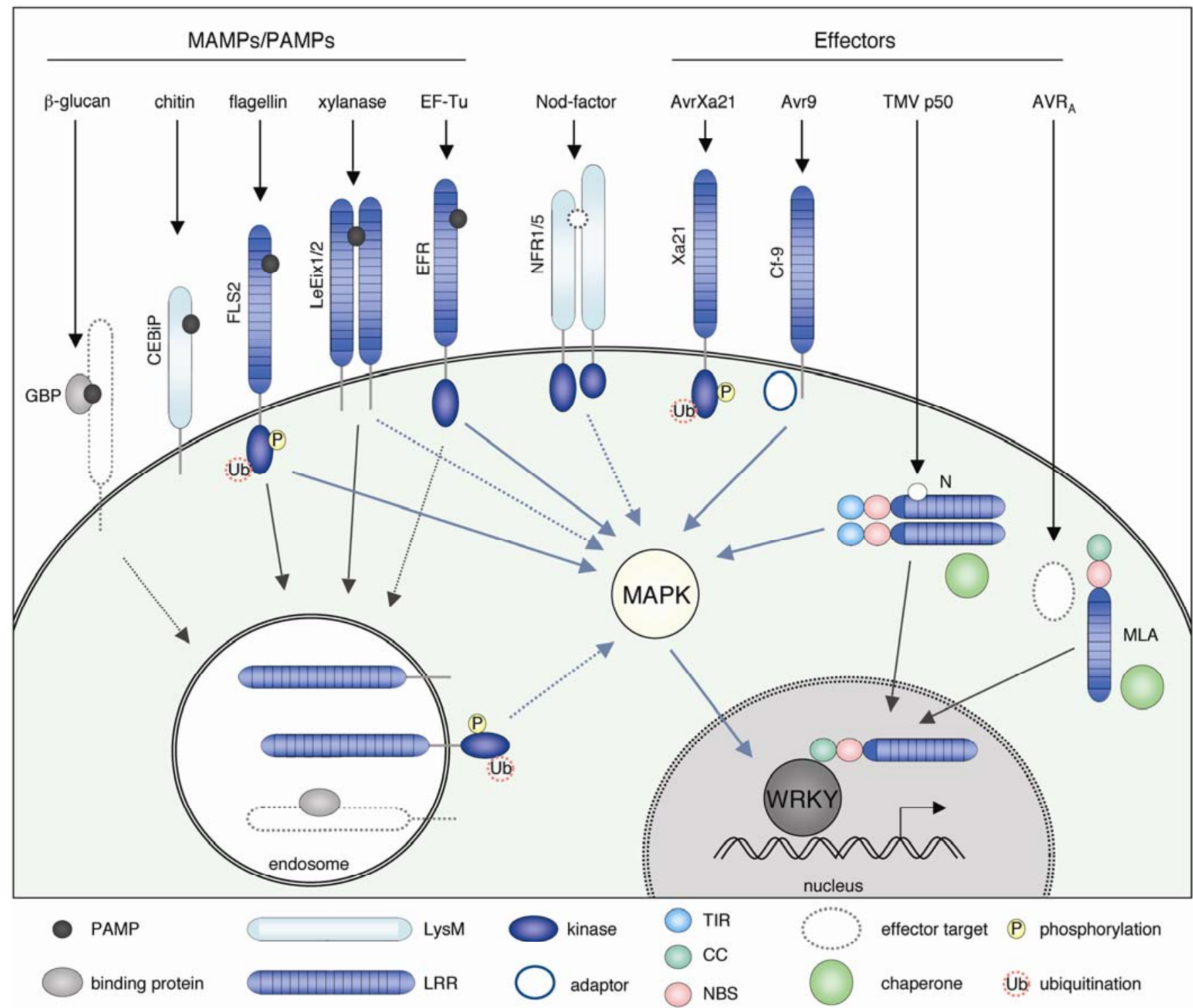

Fig. 2. Subcellular redistribution and signaling of receptors that mediate plant immunity. Microbial molecules can occur as structures conserved in whole classes of microbe-associated molecular patterns (MAMPs) or produced exclusively by a single species, or a single strain (effector). Membrane-resident receptor-like kinasees or receptor-like proteins recognize distinct MAMPs, possibly through close physical interaction, which might trigger oligomerization, subsequent phosphorylation events, and internalization into endosomes. Activated receptors might induce mitogen-activated protein kinase (MAPK) signaling (or other signaling components such as CDPK), initiated at the cell membrane or at the endosome. Finally, MAMP signaling results in transcriptional changes involving activities of WRKY transcription factors. Intracellular nucleotide-binding site leucine-rich repeats (NB-LRR) monitor effector-triggered changes (e.g., by guarding specific host proteins). Effector-activated Toll and IL-1 (TIR)-NB-LRR undergo oligomerization and can trigger MAPK signaling. NB-LRR complexes require the presence of chaperone proteins (e.g., RAR1, SGT1, and HSP90). Activated NB-LRR can translocate to the nucleus where they interact with WRKY factors controlling gene expression. The two NB-LRR depicted summarize current knowledge. Black arrows indicate trafficking routes and blue arrows highlight signaling pathways. Dashed arrows indicate putative trafficking or signaling pathways, and dashed shapes depict putative associated proteins. PAMP = pathogen-associated molecular pattern, $\mathrm{EF}-\mathrm{Tu}=$ elongation factor Tu, TMV = Tobacco mosaic virus, $\mathrm{GBP}=\beta$-glucan-binding protein, and $\mathrm{CC}=$ coiled coil . 


\section{NOTE ADDED IN PROOF}

While this manuscript was in preparation Kemmerling and associates (2007) reported a novel role for the BRI1-associated kinase 1 , BAK1, in plant defense by restricting pathogeninduced cell death. Just like ERECTA, BAK1 exhibits a dual function in development and immune responses.

Moreover, Chinchilla and associates (2007) discovered that bak1 mutants are insensitive to flg22 while remaining normal flg22 binding. They showed the FLS2 interacts with BAK1 in a flg22-dependent manner suggesting that BAK1 function is required for FLS2-mediated responses.

\section{LITERATURE CITATIONS ADDED IN PROOF}

Kemmerling, B., Schwedt, A., Rodriguez, P., Mazzotta, S., Frank, M., Quamar, S. A., Mengiste, T., Betsuyaku, S., Parker, J. E., Müssig, C. Thomma, B. P. H. J., Albrecht, C., de Vries, S., Hirt, H., and Nürnberger, T. 2007. The BRI1-associated kinase1, BAK1, has a brassinolide-independent role in plant cell-death control. Curr. Biol. doi: 10.10116/j.cub.2007.05.046. Published online.

Chinchilla, D., Zipfel, C., Robatzek, S., Kemmerling, B., Nurnberger, T., Jones, J. D. G., Felix, G., and Boller, T. 2007. A flagellin-induced complex of the receptor FLS2 and BAK1 initiates plant defense. Nature doi: 10.1038/nature05999. Published online.

\section{ACKNOWLEDGMENTS}

We thank R. O'Connell for critically reading the manuscript and T. Nurnberger for sharing unpublished results. S. Robatzek is supported by the Deutsche Forschungsgemeinschaft (SFB670).

\section{LITERATURE CITED}

Andersen-Nissen, E., Smith, K. D., Bonneau, R., Strong, R. K., and Aderem A. 2007. A conserved surface on Toll-like receptor 5 recognizes bacterial flagellin. J. Exp. Med. 204:393-403.

Arrighi, J. F., Barre, A., Ben Amor, B., Bersoult, A., Soriano, L. C., Mirabella, R., de Carvalho-Niebel, F., Journet, E. P., Gherardi, M., Huguet, T., Geurts, R., Denarie, J., Rouge, P., and Gough, C. 2006. The Medicago truncatula lysine motif-receptor-like kinase gene family includes NFP and new nodule-expressed genes. Plant Physiol. 142:265279

Asai, T., Tena, G., Plotnikova, J., Willmann, M. R., Chiu, W. L., GomezGomez, L., Boller, T., Ausubel, F. M., and Sheen, J. 2002. MAP kinase signalling cascade in Arabidopsis innate immunity. Nature 415:977983.

Bargmann, B. O. R., Laxalt, A. M., ter Riet, B., Schouten, E., van Leeuwen, W., Dekker, H. L., de Koster, C. G., Haring, M. A., and Munnik, T. 2006. LePLD $\beta 1$ activation and relocalization in suspension-cultured tomato cells treated with xylanase. Plant J. 45:358-368.

Baureithel, K., Felix, G., and Boller, T. 1994. Specific, high affinity binding of chitin fragments to tomato cells and membranes. Competitive inhibition of binding by derivatives of chitooligosaccharides and a Nod factor of Rhizobium. J. Biol. Chem. 269:17931-17938.

Bell, J. K., Askins, J., Hall, P. R., Davies, D. R., and Segal, D. M. 2006. The dsRNA binding site of human Toll-like receptor 3. Proc. Natl. Acad. Sci. U.S.A. 103:8792-8797.

Benschop, J. J., Mohammed, S., O-Flaherty, M., Heck, A. J., Slijper, M. and Menke, F. L. 2007. Quantitative phospho-proteomics of early elicitor signalling in Arabidopsis. Mol. Cell Proteomics. doi: M600429MCP200. Published online.

Brueggeman, R., Rostoks, N., Kudrna, D., Kilian, A., Han, F., Chen, J., Druka, A., Steffenson, B., and Kleinhofs, A. 2002. The barley stem rust-resistance gene Rpg1 is a novel disease-resistance gene with homology to receptor kinases. Proc. Natl. Acad. Sci. U.S.A. 99:93289333.

Brunner, F., Rosahl, S., Lee, J., Rudd, J. J., Geiler, C., Kauppinen, S., Rasmussen, G., Scheel, D., and Nurnberger, T. 2002. Pep-13, a plant defense-inducing pathogen-associated pattern from Phytophthora transglutaminases. EMBO (Eur. Mol. Biol. Organ.) J. 21:6681-6688.

Burch-Smith, T. M., Schiff, M., Caplan, J. L., Tsao, J., Czymmek, K., and Dinesh-Kumar, S. P. 2007. A novel role for the TIR domain in association with pathogen-derived elicitors. PLoS Biol. 5:e68.

Chen, X., Shang, J., Chen, D., Lei, C., Zou, Y., Zhai, W., Liu, G., Xu, J., Ling, Z., Cao, G., Ma, B., Wang, Y., Zhao, X., Li, S., and Zhu, L. 2006.
A B-lectin receptor kinase gene conferring rice blast resistance. Plant J. 46:794-804.

Chinchilla, D., Bauer, Z., Regenass, M., Boller, T., and Felix, G. 2006. The Arabidopsis receptor kinase FLS2 binds flg22 and determines the specificity of flagellin perception. Plant Cell 18:465-476.

Chinchilla, D., Boller, T., and Robatzek, S. 2007. Flagellin signaling in plant immunity. Adv. Exp. Med. Biol. 598:358-371.

Chisholm, S. T., Coaker, G., Day, B., and Staskawicz, B. J. 2006. Host-microbe interactions: Shaping the evolution of the plant immune response. Cell 124:803-814.

Choe, J., Kelker, M. S., and Wilson, I. A. 2005. Crystal structure of human toll-like receptor 3 (TLR3) ectodomain. Science 309:581-585.

Citri, A., and Yarden, Y. 2006. EGF-ERBB signalling: Towards the systems level. Nat. Rev. Mol. Cell. Biol. 7:505-516.

Deslandes, L., Olivier, J., Peeters, N., Feng, D. X., Khounlotham, M., Boucher, C., Somssich, I., Genin, S., and Marco, Y. 2003. Physical interaction between RRS1-R, a protein conferring resistance to bacterial wilt, and PopP2, a type III effector targeted to the plant nucleus. Proc. Natl. Acad. Sci. U.S.A. 100:8024-8029.

Ellis, J., Dodds, P., and Pryor, T. 2000. Structure, function and evolution of plant disease resistance genes. Curr. Opin. Plant Biol. 3:278-284.

Felix, G., and Boller, T. 2003. Molecular sensing of bacteria in plants. The highly conserved RNA-binding motif RNP-1 of bacterial cold shock proteins is recognized as an elicitor signal in tobacco. J. Biol. Chem. 278:6201-6208.

Felix, G., Duran, J. D., Volko, S., and Boller, T. 1999. Plants have a sensitive perception system for the most conserved domain of bacterial flagellin. Plant J. 18:265-276.

Fiers, M., Ku, K. L., and Liu, C. M. 2006. CLE peptide ligands and their roles in establishing meristems. Curr. Opin. Plant Biol. 10:39-43.

Fliegmann, J., Mithofer, A., Wanner, G., and Ebel, J. 2004. An ancient enzyme domain hidden in the putative beta-glucan elicitor receptor of soybean may play an active part in the perception of pathogen-associated molecular patterns during broad host resistance. J. Biol. Chem. 279:1132-1140

Fritz-Laylin, L. K., Krishnamurthy, N., Tor, M., Sjolander, K. V., and Jones, J. D. 2005. Phylogenomic analysis of the receptor-like proteins of rice and Arabidopsis. Plant Physiol. 138:611-623.

Geldner, N., and Jurgens, G. 2006. Endocytosis in signalling and development. Curr. Opin. Plant Biol. 9:589-594.

Gomez-Gomez, L., and Boller, T. 2000. FLS2: An LRR receptor-like kinase involved in the perception of the bacterial elicitor flagellin in Arabidopsis. Mol. Cell 5:1003-1011.

Gomez-Gomez, L., Bauer, Z., and Boller, T. 2001. Both the extracellular leucine-rich repeat domain and the kinase activity of FSL2 are required for flagellin binding and signaling in Arabidopsis. Plant Cell 13:1155-1163.

Granado, J., Felix, G., and Boller, T. 1995. Perception of fungal sterols in plants (subnanomolar concentrations of ergosterol elicit extracellular alkalinization in tomato cells). Plant Physiol. 107:485-490.

Grant, S. R., Fisher, E. J., Chang, J. H., Mole, B. M., and Dangl, J. L. 2006. Subterfuge and manipulation: Type III effector proteins of phytopathogenic bacteria. Annu. Rev. Microbiol. 60:425-449.

Gross, A., Kapp, D., Nielsen, T., and Niehaus, K. 2005. Endocytosis of Xanthomonas campestris pathovar campestris lipopolysaccharides in non-host plant cells of Nicotiana tabacum. New Phytol. 165:215-226.

Hammond, D. E., Urbe, S., Vande Woude, G. F., and Clague, M. J. 2001. Down-regulation of MET, the receptor for hepatocyte growth factor. Oncogene 20:2761-2770.

He, P., Shan, L., Lin, N. C., Martin, G. B., Kemmerling, B., Nurnberger, T., and Sheen, J. 2006. Specific bacterial suppressors of MAMP signaling upstream of MAPKKK in Arabidopsis innate immunity. Cell 125:563-575.

Hubbard, S. R. 1999. Structural analysis of receptor tyrosine kinases. Prog. Biophys. Mol. Biol. 71:343-358.

Hubbard, S. R., and Till, J. H. 2000. Protein tyrosine kinase structure and function. Annu. Rev. Biochem. 69:373-398.

Husebye, H., Halaas, O., Stenmark, H., Tunheim, G., Sandanger, O., Bogen, B., Brech, A., Latz, E., and Espevik, T. 2006. Endocytic pathways regulate Toll-like receptor 4 signaling and link innate and adaptive immunity. EMBO (Eur. Mol. Biol. Organ.) J. 25:683-692.

Inohara, N., and Nunez, G. 2003. NODs: Intracellular proteins involved in inflammation and apoptosis. Nat. Rev. Immunol. 3:371-382.

Jones, J. D., and Dangl, J. L. 2006. The plant immune system. Nature 444:323-329.

Kaku, H., Nishizawa, Y., Ishii-Minami, N., Akimoto-Tomiyama, C. Dohmae, N., Takio, K., Minami, E., and Shibuya, N. 2006. Plant cells recognize chitin fragments for defense signaling through a plasma membrane receptor. Proc. Natl. Acad. Sci. U.S.A. 103:11086-11091.

Karlova, R., Boeren, S., Russinova, E., Aker, J., Vervoort, J., and de Vries, S. 2006. The Arabidopsis SOMATIC EMBRYOGENESIS RECEP- 
TOR-LIKE KINASE1 protein complex includes BRASSINOSTEROID-INSENSITIVE1. Plant Cell 18:626-638.

Kawchuk, L. M., Hachey, J., Lynch, D. R., Kulcsar, F., van Rooijen, G., Waterer, D. R., Robertson, A., Kokko, E., Byers, R., Howard, R. J., Fischer, R., and Prufer, D. 2001. Tomato Ve disease resistance genes encode cell surface-like receptors. Proc. Natl. Acad. Sci. U.S.A. 98:65116515.

Keen, N. T. 1990. Gene-for-gene complementarity in plant-pathogen interactions. Annu. Rev. Genet. 24:447-463.

Kinoshita, T., Cano-Delgado, A., Seto, H., Hiranuma, S., Fujioka, S., Yoshida, S., and Chory, J. 2005. Binding of brassinosteroids to the extracellular domain of plant receptor kinase BRI1. Nature 433:167-171.

Klarzynski, O., Plesse, B., Joubert, J. M., Yvin, J. C., Kopp, M., Kloareg, B., and Fritig, B. 2000. Linear beta-1,3 glucans are elicitors of defense responses in tobacco. Plant Physiol. 124:1027-1038.

Kolade, O. O., Bamford, V. A., Ancillo Anton, G., Jones, J. D., Vera, P., and Hemmings, A. M. 2006. In vitro characterization of the cysteinerich capping domains in a plant leucine rich repeat protein. Biochim. Biophys. Acta 1764:1043-1053.

Kopp, E., and Medzhitov, R. 2003. Recognition of microbial infection by Toll-like receptors. Curr. Opin. Immunol. 15:396-401.

Kunze, G., Zipfel, C., Robatzek, S., Niehaus, K., Boller, T., and Felix, G. 2004. The $\mathrm{N}$ terminus of bacterial elongation factor Tu elicits innate immunity in Arabidopsis plants. Plant Cell 16:3496-3507.

Lee, C. S., Kim, I. S., Park, J. B., Lee, M. N., Lee, H. Y., Suh, P. G., and Ryu, S. H. 2006. The phox homology domain of phospholipase D activates dynamin GTPase activity and accelerates EGFR endocytosis. Nat. Cell Biol. 8:477-484.

Lee, S. W., Han, S. W., Bartley, L. E., and Ronald, P. C. 2006. Unique characteristics of Xanthomonas oryzae pv. oryzae AvrXa21 and implications for plant innate immunity. Proc. Natl. Acad. Sci. U.S.A. 103:18390-18400.

Ligterink, W., Kroj, T., zur Nieden, U., Hirt, H., and Scheel, D. 1997. Receptor-mediated activation of a MAP kinase in pathogen defense of plants. Science 276:2054-2057.

Lin, S. Y., Makino, K., Xia, W., Matin, A., Wen, Y., Kwong, K. Y., Bourguignon, L., and Hung, M. C. 2001. Nuclear localization of EGF receptor and its potential new role as a transcription factor. Nat. Cell Biol. 3:802-808.

Linhoff, M. W., Harton, J. A., Cressman, D. E., Martin, B. K., and Ting, J. P. 2001. Two distinct domains within CIITA mediate self-association: Involvement of the GTP-binding and leucine-rich repeat domains. Mol. Cell Biol. 21:3001-3011.

Lo, H. W., Ali-Seyed, M., Wu, Y., Bartholomeusz, G., Hsu, S. C., and Hung, M. C. 2006. Nuclear-cytoplasmic transport of EGFR involves receptor endocytosis, importin beta1 and CRM1. J. Cell Biochem. 98:1570-1583.

Mackey, D., and McFall, A. J. 2006. MAMPs and MIMPs: Proposed classifications for inducers of innate immunity. Mol. Microbiol. 61:13651371.

Madsen, E. B., Madsen, L. H., Radutoiu, S., Olbryt, M., Rakwalska, M., Szczyglowski, K., Sato, S., Kaneko, T., Tabata, S., Sandal, N., and Stougaard, J. 2003. A receptor kinase gene of the LysM type is involved in legume perception of rhizobial signals. Nature 425:637-640.

Martin, G. B., Bogdanove, A. J., and Sessa, G. 2003. Understanding the functions of plant disease resistance proteins. Annu. Rev. Plant Biol. 54:23-61.

McCoy, S. L., Kurtz, S. E., Hausman, F. A., Trune, D. R., Bennett, R. M., and Hefeneider, S. H. 2004. Activation of RAW264.7 macrophages by bacterial DNA and lipopolysaccharide increases cell surface DNA binding and internalization. J. Biol. Chem. 279:17217-17223.

McHale, L., Tan, X., Koehl, P., and Michelmore, R. W. 2006. Plant NBSLRR proteins: Adaptable guards. Genome Biol. 7:212.

Meindl, T., Boller, T., and Felix, G. 2000. The bacterial elicitor flagellin activates its receptor in tomato cells according to the address-message concept. Plant Cell 12:1783-1794.

Melotto, M., Underwood, W., Koczan, J., Nomura, K., and He, S. Y. 2006. Plant stomata function in innate immunity against bacterial invasion. Cell 126:969-980.

Meyer, A., Puhler, A., and Niehaus, K. 2001. The lipopolysaccharides of the phytopathogen Xanthomonas campestris pv. campestris induce an oxidative burst reaction in cell cultures of Nicotiana tabacum. Planta 213:214-222.

Meyers, B. C., Kozik, A., Griego, A., Kuang, H., and Michelmore, R. W. 2003. Genome-wide analysis of NBS-LRR-encoding genes in Arabidopsis. Plant Cell 15:809-834.

Montoya, T., Nomura, T., Farrar, K., Kaneta, T., Yokota, T., and Bishop, G. J. 2002. Cloning the tomato curl3 gene highlights the putative dual role of the leucine-rich repeat receptor kinase tBRI1/SR160 in plant steroid hormone and peptide hormone signaling. Plant Cell 14:3163-3176.
Mulder, L., Lefebvre, B., Cullimore, J., and Imberty, A. 2006. LysM domains of Medicago truncatula NFP protein involved in Nod factor perception. Glycosylation state, molecular modeling and docking of chitooligosaccharides and Nod factors. Glycobiology 16:801-809.

Nekrasov, V., Ludwig, A. A., and Jones, J. D. 2006. CITRX thioredoxin is a putative adaptor protein connecting Cf- 9 and the ACIK1 protein kinase during the Cf-9/Avr9- induced defence response. FEBS (Fed. Eur. Biochem. Soc.) Lett. 580:4236-4241.

Ni, C. Y., Murphy, M. P., Golde, T. E., and Carpenter, G. 2001. $\gamma$ Secretase cleavage and nuclear localization of ErbB-4 receptor tyrosine kinase. Science 294:2179-2181.

Nuhse, T. S., Stensballe, A., Jensen, O. N., and Peck, S. C. 2004. Phosphoproteomics of the Arabidopsis plasma membrane and a new phosphorylation site database. Plant Cell 16:2394-2405.

Nurnberger, T., Brunner, F., Kemmerling, B., and Piater, L. 2004. Innate immunity in plants and animals: Striking similarities and obvious differences. Immunol. Rev. 198:249-266.

Ozinsky, A., Underhill, D. M., Fontenot, J. D., Hajjar, A. M., Smith, K. D., Wilson, C. B., Schroeder, L., and Aderem, A. 2000. The repertoire for pattern recognition of pathogens by the innate immune system is defined by cooperation between toll-like receptors. Proc. Natl. Acad. Sci. U.S.A. 97:13766-13771.

Palma, K., Zhang, Y., and Li, X. 2005. An importin alpha homolog, MOS6, plays an important role in plant innate immunity. Curr. Biol. 15:1129-1135.

Radutoiu, S., Madsen, L. H., Madsen, E. B., Felle, H. H., Umehara, Y. Gronlund, M., Sato, S., Nakamura, Y., Tabata, S., Sandal, N., and Stougaard, J. 2003. Plant recognition of symbiotic bacteria requires two LysM receptor-like kinases. Nature 425:585-592.

Rast, J. P., Smith, L. C., Loza-Coll, M., Hibino, T., and Litman, G. W. 2006. Genomic insights into the immune system of the sea urchin. Science 314:952-956.

Riely, B. K., Ane, J. M., Penmetsa, R. V., and Cook, D. R. 2004. Genetic and genomic analysis in model legumes bring Nod-factor signaling to center stage. Curr. Opin. Plant Biol. 7:408-413.

Rivas, S., and Thomas, C. M. 2005. Molecular interactions between tomato and the leaf mold pathogen Cladosporium fulvum. Annu. Rev. Phytopathol. 43:395-436.

Robatzek, S., Chinchilla, D., and Boller, T. 2006. Ligand-induced endocytosis of the pattern recognition receptor FLS2 in Arabidopsis. Genes Dev. 20:537-542.

Robatzek, S., Bittel, P., Chinchilla, D., Kochner, P., Felix, G., Shiu, S. H., and Boller, T. 2007. Molecular identification and characterization of the tomato flagellin receptor LeFLS2, an orthologue of Arabidopsis FLS2 exhibiting characteristically different perception specificities. Plant Mol. Biol. 64:539-547.

Romeis, T., Tang, S., Hammond-Kosack, K. E., Piedras, P., Blatt, M., and Jones, J. D. G. 2000. Early signalling events in the Avr9/Cf-9-dependent plant defence response. Mol. Plant Pathol. 1:3-8

Ron, M., and Avni, A. 2004. The receptor for the fungal elicitor ethyleneinducing xylanase is a member of a resistance-like gene family in tomato. Plant Cell 16:1604-1615.

Rooney, H. C., Van't Klooster, J. W., van der Hoorn, R. A., Joosten, M. H., Jones, J. D., and de Wit, P. J. 2005. Cladosporium Avr2 inhibits tomato Rcr3 protease required for Cf-2-dependent disease resistance. Science 308:1783-1786.

Russinova, E., Borst, J. W., Kwaaitaal, M., Cano-Delgado, A., Yin, Y., Chory, J., and de Vries, S. C. 2004. Heterodimerization and endocytosis of Arabidopsis brassinosteroid receptors BRI1 and AtSERK3 (BAK1). Plant Cell 16:3216-3229.

Sanabria, N. M., and Dubery, I. A. 2006. Differential display profiling of the Nicotiana response to LPS reveals elements of plant basal resistance. Biochem. Biophys. Res. Commun. 344:1001-1007.

Schlessinger, J. 2000. Cell signaling by receptor tyrosine kinases. Cell 103:211-225.

Serrano, M., Robatzek, S., Torres, M., Kombrink, E., Somssich, I. E., Robinson, M., and Schulze-Lefert, P. 2007. Chemical interference of pathogen-associated molecular pattern-triggered immune responses in Arabidopsis reveals a potential role for fatty-acid synthase type II complex-derived lipid signals. J. Biol. Chem. 282:6803-6811.

Shah, K., Russinova, E., Gadella, T. W., Jr., Willemse, J., and De Vries, S. C. 2002. The Arabidopsis kinase-associated protein phosphatase controls internalization of the somatic embryogenesis receptor kinase 1. Genes Dev. 16:1707-1720.

Shen, Q. H., Saijo, Y., Mauch, S., Biskup, C., Bieri, S., Keller, B., Seki, H., Ulker, B., Somssich, I. E., and Schulze-Lefert, P. 2007. Nuclear activity of MLA immune receptors links isolate-specific and basal disease-resistance responses. Science 315:1098-1103.

Shi, Y., and Massague, J. 2003. Mechanisms of TGF-beta signaling from cell membrane to the nucleus. Cell 113:685-700. 
Shiu, S. H., and Bleecker, A. B. 2003. Expansion of the receptor-like kinase/Pelle gene family and receptor-like proteins in Arabidopsis. Plant Physiol. 132:530-543.

Skorpil, P., Saad, M. M., Boukli, N. M., Kobayashi, H., Ares-Orpel, F., Broughton, W. J., and Deakin, W. J. 2005. NopP, a phosphorylated effector of Rhizobium sp. strain NGR234, is a major determinant of nodulation of the tropical legumes Flemingia congesta and Tephrosia vogelii. Mol. Microbiol. 57:1304-1317.

Smith, K. D., Andersen-Nissen, E., Hayashi, F., Strobe, K., Bergman, M A., Barrett, S. L., Cookson, B. T., and Aderem, A. 2003. Toll-like receptor 5 recognizes a conserved site on flagellin required for protofilament formation and bacterial motility. Nat. Immunol. 4:1247-1253.

Soosaar, J. L., Burch-Smith, T. M., and Dinesh-Kumar, S. P. 2005. Mechanisms of plant resistance to viruses. Nat. Rev. Microbiol. 3:789-798.

Sun, W., Dunning, F. M., Pfund, C., Weingarten, R., and Bent, A. F. 2006. Within-species flagellin polymorphism in Xanthomonas campestris pv. campestris and its impact on elicitation of Arabidopsis FLAGELLIN SENSING2-dependent defenses. Plant Cell 18:764-779.

Sun, X., Cao, Y., Yang, Z., Xu, C., Li, X., Wang, S., and Zhang, Q. 2004. Xa26, a gene conferring resistance to Xanthomonas oryzae pv. oryzae in rice, encodes an LRR receptor kinase-like protein. Plant J. 37:517-527.

Takeda, K. 2005. Evolution and integration of innate immune recognition systems: The Toll-like receptors. J. Endotoxin Res. 11:51-55.

Takeda, K., and Akira, S. 2003. Toll receptors and pathogen resistance. Cell Microbiol. 5:143-153.

Takken, F. L., Thomas, C. M., Joosten, M. H., Golstein, C., Westerink, N., Hille, J., Nijkamp, H. J., De Wit, P. J., and Jones, J. D. 1999. A second gene at the tomato $\mathrm{Cf}-4$ locus confers resistance to Cladosporium fulvum through recognition of a novel avirulence determinant. Plant $\mathrm{J}$. 20:279-288

Teis, D., Wunderlich, W., and Huber, L. A. 2002. Localization of the MP1MAPK scaffold complex to endosomes is mediated by p14 and required for signal transduction. Dev. Cell 3:803-814.

Ting, J. P., Kastner, D. L., and Hoffman, H. M. 2006. CATERPILLERs, pyrin and hereditary immunological disorders. Nat. Rev. Immunol. 6:183-195.

Underhill, D. M. 2003. Toll-like receptors: Networking for success. Eur. J. Immunol. 33:1767-1775.

van der Hoorn, R. A., Wulff, B. B., Rivas, S., Durrant, M. C., van der Ploeg, A., de Wit, P. J., and Jones, J. D. 2005. Structure-function analysis of $\mathrm{cf}-9$, a receptor-like protein with extracytoplasmic leucine-rich repeats. Plant Cell 17:1000-1015.

Vieira, A. V., Lamaze, C., and Schmid, S. L. 1996. Control of EGF receptor signaling by clathrin-mediated endocytosis. Science 274:2086-2089.
Viprey, V., Del Greco, A., Golinowski, W., Broughton, W. J., and Perret, X 1998. Symbiotic implications of type III protein secretion machinery in Rhizobium. Mol. Microbiol. 28:1381-1389.

Wang, G. L., Song, W. Y., Ruan, D. L., Sideris, S., and Ronald, P. C. 1996. The cloned gene, $\mathrm{Xa} 21$, confers resistance to multiple Xanthomonas oryzae pv. oryzae isolates in transgenic plants. Mol. Plant-Microbe Interact. 9:850-855.

Wang, X., Li, X., Meisenhelder, J., Hunter, T., Yoshida, S., Asami, T. and Chory, J. 2005. Autoregulation and homodimerization are involved in the activation of the plant steroid receptor BRI1. Dev. Cell 8:855865.

Wang, Y. S., Pi, L. Y., Chen, X., Chakrabarty, P. K., Jiang, J., De Leon, A L., Liu, G. Z., Li, L., Benny, U., Oard, J., Ronald, P. C., and Song, W. Y. 2006. Rice XA21 binding protein 3 is a ubiquitin ligase required for full Xa21-mediated disease resistance. Plant Cell. 18:3635-3646.

Wang, Z. Y., Seto, H., Fujioka, S., Yoshida, S., and Chory, J. 2001. BRI1 is a critical component of a plasma-membrane receptor for plant steroids. Nature 410:380-383.

Warren, C. M., and Landgraf, R. 2006. Signaling through ERBB receptors: Multiple layers of diversity and control. Cell Signal 18:923-933.

Xu, W. H., Wang, Y. S., Liu, G. Z., Chen, X., Tinjuangjun, P., Pi, L. Y., and Song, W. Y. 2006. The autophosphorylated Ser686, Thr688, and Ser689 residues in the intracellular juxtamembrane domain of XA21 are implicated in stability control of rice receptor-like kinase. Plant J. 45:740751.

Yamaguchi, Y., Pearce, G., and Ryan, C. A. 2006. The cell surface leucinerich repeat receptor for AtPep1, an endogenous peptide elicitor in Arabidopsis, is functional in transgenic tobacco cells. Proc. Natl. Acad. Sci. U.S.A. 103:10104-10109.

Yoshida, S., and Parniske, M. 2005. Regulation of plant symbiosis receptor kinase through serine and threonine phosphorylation. J. Biol. Chem. 280:9203-9209.

Zhang, Y., and Li, X. 2005. A putative nucleoporin 96 is required for both basal defense and constitutive resistance responses mediated by suppressor of npr1-1,constitutive 1. Plant Cell 17:1306-1316.

Zipfel, C., and Felix, G. 2005. Plants and animals: A different taste for microbes? Curr. Opin. Plant Biol. 8:353-360.

Zipfel, C., Robatzek, S., Navarro, L., Oakeley, E. J., Jones, J. D., Felix, G. and Boller, T. 2004. Bacterial disease resistance in Arabidopsis through flagellin perception. Nature 428:764-767.

Zipfel, C., Kunze, G., Chinchilla, D., Caniard, A., Jones, J. D., Boller, T., and Felix, G. 2006. Perception of the bacterial PAMP EF-Tu by the receptor EFR restricts Agrobacterium-mediated transformation. Cell 125:749-760 